\title{
HIKESHI silencing can enhance mild hyperthermia sensitivity in human oral squamous cell carcinoma HSC-3 cells
}

\author{
YOSHIAKI TABUCHI $^{1,2}$, KEITA MAEKAWA ${ }^{1}$, MISAKO TORIGOE $^{3}$, YUKIHIRO FURUSAWA $^{4}$, \\ TETSUSHI HIRANO $^{1}$, SATSUKI MINAGAWA ${ }^{1}$, TATSUYA YUNOKI ${ }^{3}$ and ATSUSHI HAYASHI ${ }^{3}$ \\ ${ }^{1}$ Division of Molecular Genetics Research, Life Science Research Center, University of Toyama, \\ Toyama 930-0194; ${ }^{2}$ Graduate School of Innovative Life Science, University of Toyama, Toyama 930-8555; \\ ${ }^{3}$ Department of Ophthalmology, Graduate School of Medicine and Pharmaceutical Sciences, University of Toyama, \\ Toyama 930-0194; ${ }^{4}$ Department of Liberal Arts and Sciences, Toyama Prefectural University, Toyama 939-0398, Japan
}

Received December 19, 2019; Accepted March 9, 2020

DOI: $10.3892 / \mathrm{ijmm} .2020 .4591$

\begin{abstract}
Hyperthermia (HT) is considered to be of value as a treatment modality in various cancers. However, the acquisition of thermotolerance in cancer cells due to the induction of heat shock proteins (HSPs) makes HT less effective. Recent findings have indicated that heat shock protein nuclear import factor hikeshi (HIKESHI), also referred to as $\mathrm{C} 11$ orf 73 , acts as a nuclear import carrier of Hsp70 under heat stress conditions. The aim of the present study was to determine whether knockdown (KD) of HIKESHI by small interfering RNA (siRNA) can potentiate mild HT (MHT) sensitivity in human oral squamous cell carcinoma (OSCC) HSC-3 cells. The mRNA and protein expression of HIKESHI was found to be markedly suppressed in HSC-3 cells treated with siRNA for HIKESHI (siHIKE). Silencing HIKESHI significantly decreased the cell viability under
\end{abstract}

Correspondence to: Professor Yoshiaki Tabuchi, Division of Molecular Genetics Research, Life Science Research Center, University of Toyama, 2630 Sugitani, Toyama 930-0194, Japan E-mail: ytabu@cts.u-toyama.ac.jp

Abbreviations: DNAJ, DnaJ (Hsp40) homolog; FBL, fibrillarin; FBS, fetal bovine serum; GAPDH, glyceraldehyde 3-phosphate dehydrogenase; HIKESHI, heat shock protein nuclear import factor hikeshi; HSF1, heat shock transcription factor 1; HSP90, heat shock protein 90; HSPA, heat shock $70 \mathrm{kDa}$ protein; HSPB, heat shock $27 \mathrm{kDa}$ protein; HSPD, heat shock $60 \mathrm{kDa}$ protein; HSPH, heat shock $105 \mathrm{kDa} / 110 \mathrm{kDa}$ protein; HSPs, heat shock proteins; HT, hyperthermia; KD, knockdown; MAPK/ERK, mitogen-activated protein kinase/extracellular signal-regulated kinase; MHT, mild HT; OSCC, oral squamous cell carcinoma; pERK1/2, phosphorylated ERK1/2; siRNA, small interfering RNA; siHIKE, siRNA for HIKESHI; siLuc, siRNA for luciferase

Key words: mild hyperthermia, HIKESHI knockdown, heat shock protein 70 , extracellular signal-regulated kinase 2, human oral squamous cell carcinoma HSC-3 cells
MHT conditions $\left(42^{\circ} \mathrm{C}\right.$ for $\left.90 \mathrm{~min}\right)$. Immunocytochemical and western blot analyses clearly demonstrated that Hsp70 protein translocated from the cytoplasm to the nucleus under MHT conditions, and this translocation was significantly inhibited in cells treated with siHIKE. Treatment of the cells with MHT transiently increased the phosphorylation level of extracellular signal-regulated kinase (ERK)2. Furthermore, the phosphorylation was sustained in HIKESHI-KD cells under MHT conditions, and this sustained phosphorylation was abolished by pretreatment with U0126, an inhibitor of mitogen-activated protein kinase/ERK. In addition, U0126 significantly decreased the viability of cells treated with the combination of HIKESHI-KD and MHT. The data of the present study suggest that HIKESHI silencing enhanced the sensitivity of human OSCC HSC-3 cells to MHT.

\section{Introduction}

The use of hyperthermia (HT) has been gradually increasing over the past three decades. In general, temperatures ranging from 40 to $45^{\circ} \mathrm{C}$ are used in locoregional treatment, whereas temperatures of up to $42^{\circ} \mathrm{C}$ are used in cases requiring whole-body HT. HT combined with chemotherapy, radiotherapy, or both, is considered as a promising approach to cancer therapy (1-10). However, the thermotolerance due to the upregulation of heat shock proteins (HSPs) in some cancer cells is a limiting factor that reduces the efficacy of HT in the clinical setting (11-15).

HSPs are highly conserved proteins occurring in almost all organisms and they are classified by their molecular weight; these include heat shock $27 \mathrm{kDa}$ protein (HSPB), DnaJ (Hsp40) homolog (DNAJ), heat shock $60 \mathrm{kDa}$ protein (HSPD), heat shock $70 \mathrm{kDa}$ protein (HSPA), heat shock protein 90 (HSP90) and heat shock 105/110 kDa protein (HSPH) in humans. HSPs act as molecular chaperones, and their expression is induced by various stressors, including heat (16-20). The induction of HSPs principally occurs through the activation of heat shock transcription factor 1 (HSF1), which binds to conserved regulatory sequences, referred to as heat shock elements, which are located in the promoter regions of inducible HSP genes $(21,22)$. It has 
been well established that HSPs, particularly Hsp70, exert a cytoprotective effect against stressors and play a key role in the development of thermotolerance $(19,23)$. Several studies demonstrated that abrogation of HSF1 (24,25), Hsp70 (26) or Hsp105 (27) expression increased the sensitivity of human cancer cells to heat stress. In response to heat stress, Hsp70 rapidly translocates from the cytoplasm into the nucleus $(28,29)$. Kose et al (30) reported for the first time that the nuclear import of Hsp70 is mediated by the heat shock protein nuclear import factor hikeshi (HIKESHI), also referred to as $\mathrm{C} 11$ orf 73 , under conditions of heat-induced stress. Although silencing of HIKESHI had no discernible effect under normal conditions, it was found to significantly inhibit the nuclear translocation of Hsp70 or to reduce cell viability after exposure of cancer cells to heat stress (30-32). In human gastric cancer tissues, HIKESHI expression was reported to be associated with the progression of lymphatic invasion (32). It has also been demonstrated that HIKESHI is abundantly expressed in human clear cell renal cancer (33).

In our previous studies, we used human oral squamous cell carcinoma (OSCC) HSC-3 cells as a model for evaluation of HT sensitivity $(25,34-36)$. The aim of the present study was to evaluate the effects of HIKESHI knockdown (KD) on the sensitivity of human OSCC HSC-3 cells to mild HT (MHT).

\section{Materials and methods}

Cell culture. Human HSC-3 OSCC cells (JCRB0623) were obtained from the Human Science Research Resources Bank, Japan Health Sciences Foundation (Tokyo, Japan). HSC-3 cells were cultured in Eagle's minimum essential medium (E-MEM; Wako Pure Chemical Industries, Ltd.) supplemented with $10 \%$ fetal bovine serum (FBS; Equitech-Bio, Inc.) at $37^{\circ} \mathrm{C}$ in a humidified atmosphere with $5 \% \mathrm{CO}_{2}$ and $95 \%$ air. U0126 (Cell Signaling Technology, Inc.), an inhibitor of mitogen-activated protein kinase (MAPK)/extracellular signal-regulated kinase (ERK), was dissolved in dimethyl sulfoxide and added to the culture medium $1 \mathrm{~h}$ before MHT treatment (final concentration of U0126: $10 \mu \mathrm{M})$.

MHT treatment. MHT treatments were performed by immersing plastic culture dishes sealed with laboratory film (Parafilm ${ }^{\circledR}$ M; Nippon Genetics, Co., Ltd.) in a water bath at $42^{\circ} \mathrm{C}$ for 60 or $90 \mathrm{~min}$. After MHT treatment, the cells were recovered at $37^{\circ} \mathrm{C}$ for the indicated periods.

Small interfering RNA (siRNA) transfection. Based on the human HIKESHI nucleotide database (GenBank accession no. NM_016401), two siRNAs for HIKESHI, designated as siHIK-1 and siHIK-2, were synthesized by Nippon Gene Co., Ltd. Firefly luciferase siRNA (siLuc) was used as a negative control siRNA. The sequences of the siRNAs are listed in Table I. Cells were incubated in Opti-MEM ${ }^{\circledR}$ I Reduced Serum Medium (Life Technologies Japan; Thermo Fisher Scientific, Inc.) containing $20 \mathrm{nM}$ siRNA and Lipofectamine ${ }^{\mathrm{TM}}$ RNAiMAX (Life Technologies Japan; Thermo Fisher Scientific, Inc.) at $37^{\circ} \mathrm{C}$. At $6 \mathrm{~h}$ after transfection, the medium was exchanged for E-MEM supplemented with $10 \% \mathrm{FBS}$, and then the cells were maintained at $37^{\circ} \mathrm{C}$ for 2 days (36).
Cellular fractionation. Nuclear and cytoplasmic fractions were prepared as described previously (37). In brief, the cells were lysed in the fractionation buffer [phosphate-buffered saline containing $0.1 \%$ Nonidet P-40 and protease inhibitor cocktail (Nacalai Tesque, Inc.)] and centrifuged at 15,000 x g for $10 \mathrm{sec}$ at $4^{\circ} \mathrm{C}$ to obtain the cytosolic fraction (supernatant). The insoluble pellets were resuspended in the fractionation buffer and centrifuged at $15,000 \mathrm{x}$ for $10 \mathrm{sec}$ at $4^{\circ} \mathrm{C}$ to obtain the nuclear fraction (pellets). Either GAPDH (38) or fibrillarin (FBL) (39) was used as the cytoplasmic or nuclear marker protein, respectively.

Analysis of cell viability. A trypan blue dye exclusion test was performed to assess cell viability. The number of cells excluding the dye was counted by using a hematocytometer (Burker-Turk; ERMA Inc.). Cell Count Reagent SF (Nacalai Tesque, Inc.), a water-soluble tetrazolium salt (WST-8)-based assay, was also used to test the cell viability. Cells were incubated with the WST- 8 solution at $37^{\circ} \mathrm{C}$. After $30 \mathrm{~min}$, the concentration of formazan dye was determined from the absorbance at $450 \mathrm{~nm}$.

SDS-PAGE and western blotting. Cells were lysed with lysis buffer $(50 \mathrm{mM} \mathrm{NaCl}, 1 \%$ Nonidet P-40 and $50 \mathrm{mM}$ Tris-HCl, $\mathrm{pH}$ 8.0) containing protease inhibitor cocktail (Nacalai Tesque, Inc.) and treated at $94^{\circ} \mathrm{C}$ for $3 \mathrm{~min}$. Proteins (10 $\mu \mathrm{g} /$ lane) were separated by 10 or $12.5 \%$ SDS-PAGE and transferred onto a PVDF membrane. Membranes were blocked by PVDF Blocking Reagent (Toyobo Co., Ltd.) for $3 \mathrm{~h}$ at $25^{\circ} \mathrm{C}(40,41)$. The protein concentration was determined by a standard BCA protein assay. Proteins were detected using the following primary antibodies: Mouse monoclonal anti-Hsp70 antibody (1:2,000 dilution, cat. no. SR-B810; Medical \& Biological Laboratories Co., Ltd.), rabbit polyclonal anti-HIKESHI antibody (1:1,000 dilution, cat. no. 14808-1-AP; ProteinTech Group, Inc.), rabbit polyclonal anti-HSF1 antibody (1:2,000 dilution, cat. no. 4356; Cell Signaling Technology, Inc.), mouse monoclonal anti-total ERK1/2 antibody $(1: 3,000$ dilution, cat. no. 9107, Cell Signaling Technology, Inc.), anti-phospho-ERK1/2 (Thr202/Tyr204) (pERK1/2) rabbit monoclonal antibody (1:3,000 dilution, cat. no. 4370, Cell Signaling Technology, Inc.), rabbit monoclonal anti-FBL antibody (1:2,000 dilution, cat. no. 2639; Cell Signaling Technology, Inc.) and mouse monoclonal anti-GAPDH antibody (as a loading reference; 1:2,000 dilution, cat. no. MAB347; EMD Millipore). Secondary fluorescent IRDye-conjugated anti-rabbit and anti-mouse antibodies (1:10,000 dilution, LI-COR Biosciences) were also used. Fluorescence images were acquired using an Odyssey Infrared Imager (LI-COR Biosciences), and the band density was quantified using Image Studio 5.1 software (LI-COR Biosciences).

Immunocytochemistry. Cells were grown in a collagen type I-precoated glass coverslip (AGC Techno Glass Co., Ltd.). The cells were fixed in 4\% paraformaldehyde phosphate-buffered solution (Nacalai Tesque, Inc.) for $15 \mathrm{~min}$ at $25^{\circ} \mathrm{C}$. The cells were incubated with a mouse monoclonal anti-Hsp70 antibody (1:200 dilution, cat. no. SR-B810; Medical \& Biological Laboratories Co., Ltd.) for $18 \mathrm{~h}$ at $4^{\circ} \mathrm{C}$, followed by $\mathrm{Chromeo}^{\mathrm{TM}}$ 
Table I. Nucleotide sequences of siRNAs for HIKESHI and luciferase.

\begin{tabular}{llcc}
\hline Name & \multicolumn{1}{c}{ Sequence-TT } & Position & GenBank accession nos. \\
\hline siHIK-1 & AUUACCUACAGGAGUCUGC & 607 & NM_016401 \\
siHIK-2 & AAGAAAAGUAGACAGAUCC & 392 & NM_016401 \\
siluc & CGUACGCGGAAUACUUCGA & 282 & MH759210 \\
\hline
\end{tabular}

siHIK-1, siRNA for human HIKESHI-1; siHIK-2, siRNA for human HIKESHI-2; siLuc, siRNA for luciferase; HIKESHI, heat shock protein nuclear import factor hikeshi.

Table II. Nucleotide sequences of primers for target genes.

\begin{tabular}{lllc}
\hline Genes & Orientation & \multicolumn{1}{c}{ Nucleotide sequence (5'-3') } & GenBank accession nos. \\
\hline DNAJB1 & Sense & ACCCGGACAAGAACAAGGAG & NM_006145 \\
& Antisense & GCCACCGAAGAACTCAGCAA & NM_002046 \\
GAPDH & Sense & AAGGCTGGGGCTCATTTGCA & \\
& Antisense & ATGACCTTGCCCACAGCCTT & NM_016401 \\
HIKESHI & Sense & AGGGAATGGGAGGATCTGTC & NM_005346 \\
& Antisense & GATGTTGGCTTCCTTCTCCA & \\
\hline
\end{tabular}

DNAJB1, DnaJ (Hsp40) homolog, subfamily B, member 1; GAPDH, glyceraldehyde-3-phosphate dehydrogenase; HIKESHI, heat shock protein nuclear import factor hikeshi; HSPA1, heat shock $70 \mathrm{kDa}$ protein 1.

488-labeled secondary antibody (1:500 dilution, cat. no. 15031; Active Motif) for $1 \mathrm{~h}$ at $25^{\circ} \mathrm{C}$. The nucleus was stained for $5 \mathrm{~min}$ at $25^{\circ} \mathrm{C}$ with DAPI. Immunofluorescence images were visualized by using a fluorescence microscope at a magnification of x20 (BX-50; Olympus Corporation). Fluorescence intensity was measured using softWoRx Explorer software, version 1.3 (Applied Precision, Inc.).

Reverse transcription-quantitative PCR (RT-qPCR) assay. Total RNA was extracted from cells using a NucleoSpin ${ }^{\circledast}$ RNA isolation kit (Takara Bio, Inc.). RNA quality was analyzed using a Bioanalyzer 2100 (Agilent Technologies, Inc.). Complementary DNA (cDNA) was produced from the reverse transcription of total RNA using a PrimeScript RT kit (Takara Bio Inc.) with random 6-mers and an oligo dT primer. qPCR was performed on a Mx3005P real-time PCR system (Agilent Technologies, Inc.) using a SYBR ${ }^{\circledR}$ Premix Ex Taq $^{\mathrm{TM}}$ II kit (Takara Bio, Inc.). The thermocycling conditions for each primer consisted of $10 \mathrm{~min}$ at $95^{\circ} \mathrm{C}$ followed by 40 cycles of $10 \mathrm{sec}$ at $95^{\circ} \mathrm{C}$ and $40 \mathrm{sec}$ at $60^{\circ} \mathrm{C}$. The specific primers are listed in Table II. GAPDH was used for normalization (40).

Statistical analysis. Data are shown as means \pm standard deviation. Differences between groups were analyzed by ANOVA, and correction for multiple comparisons was made using Tukey's post hoc test. Comparisons between two groups were made by using Student's t-test. $\mathrm{P}<0.05$ was considered to indicate statistically significant differences.

\section{Results}

Effects of HIKESHI-KD on the viability in HSC-3 cells. To evaluate the ability of siHIK-1 and siHIK-2 to inhibit HIKESHI expression, RT-qPCR and western blot analyses were carried out. The treatment of HSC-3 cells with siLuc did not alter the mRNA and protein expression of HIKESHI (Fig. S1). Therefore, siLuc treatment was used as control in further experiments. As shown in Fig. 1A, the two siRNAs for HIKESHI markedly reduced the mRNA expression level of HIKESHI in HSC-3 cells. This silencing was confirmed by western blotting, whereas the inhibition percentage was $\sim 85 \%$ (Fig. 1B and C). There was no difference in the silencing efficiency between the two siHIKs. Next, the effects of HIKESHI-KD on the cell growth under normal conditions were monitored. Treatment of the cells with the siRNAs for HIKESHI did not change the cell number at $37^{\circ} \mathrm{C}$ (Fig. 1D). With respect to MHT, the viability of cells exposed to MHT $\left(42^{\circ} \mathrm{C}\right.$ for $\left.90 \mathrm{~min}\right)$ alone was slightly decreased compared with that of non-treated cells; the mean values were 73 and $92 \%$ by trypan blue dye exclusion test and WST- 8 assay, respectively. HIKESHI-KD prior to MHT further decreased the number of viable cells, with mean values of $\sim 55$ and $75 \%$ by trypan blue dye exclusion test and WST- 8 assay, respectively (Fig. 2).

Effects of HIKESHI-KD on the localization of Hsp70 in HSC-3 cells. As demonstrated in Fig. 3A, Hsp70 was principally localized in the cytosolic compartment, and neither 
A

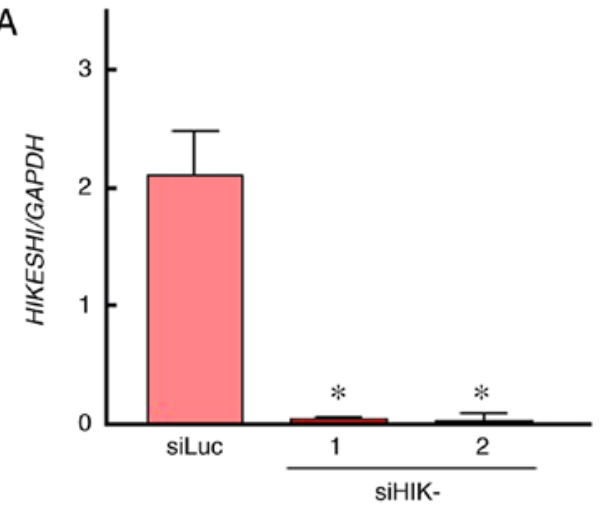

C

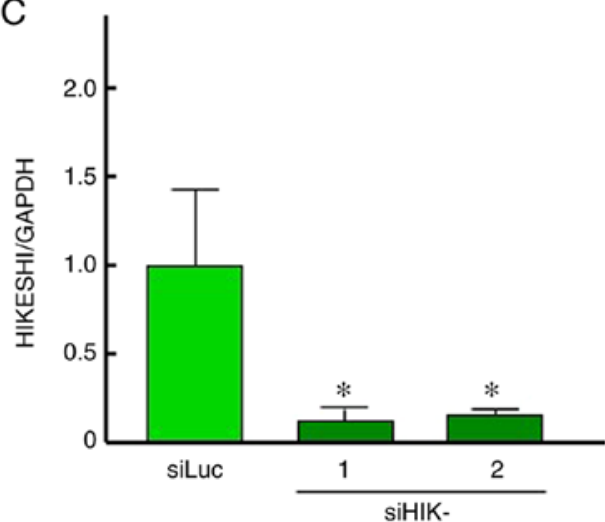

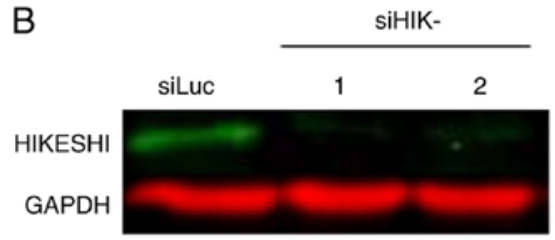

D

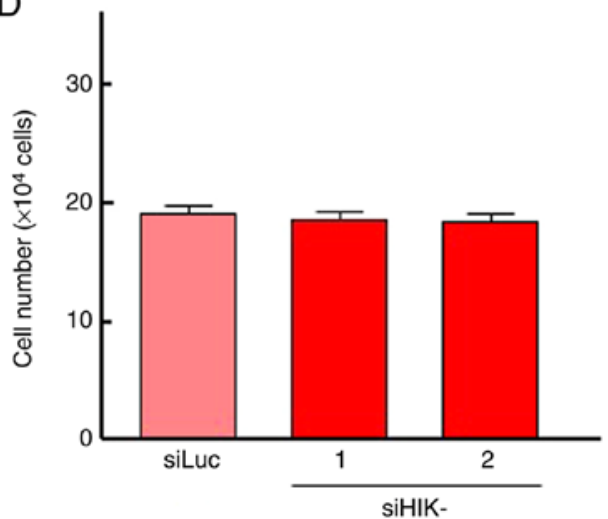

Figure 1. (A-C) Inhibition of HIKESHI mRNA and protein expression by HIKESHI siRNA in human oral squamous cell carcinoma HSC-3 cells. Cells transfected with siLuc (siRNA for luciferase) or siHIKE-1 and siHIKE-2 (siRNAs for HIKESHI) were maintained at $37^{\circ} \mathrm{C}$. At $48 \mathrm{~h}$ after transfection, the cells were harvested. The expression levels of (A) mRNA and (B) protein were detected by quantitative PCR and western blot analyses, respectively. The level of HIKESHI was normalized to the expression level of GAPDH. (C) The protein band intensity was assessed using densitometry. (D) Effects of knockdown of HIKESHI on the cell growth under non-stress conditions at $37^{\circ} \mathrm{C}$. The number of viable cells was measured using the trypan blue dye exclusion test. Data are presented as means \pm standard deviation $(n=4) .{ }^{~} \mathrm{P}<0.05$ vs. the control (siLuc treatment). HIKESHI, heat shock protein nuclear import factor hikeshi.
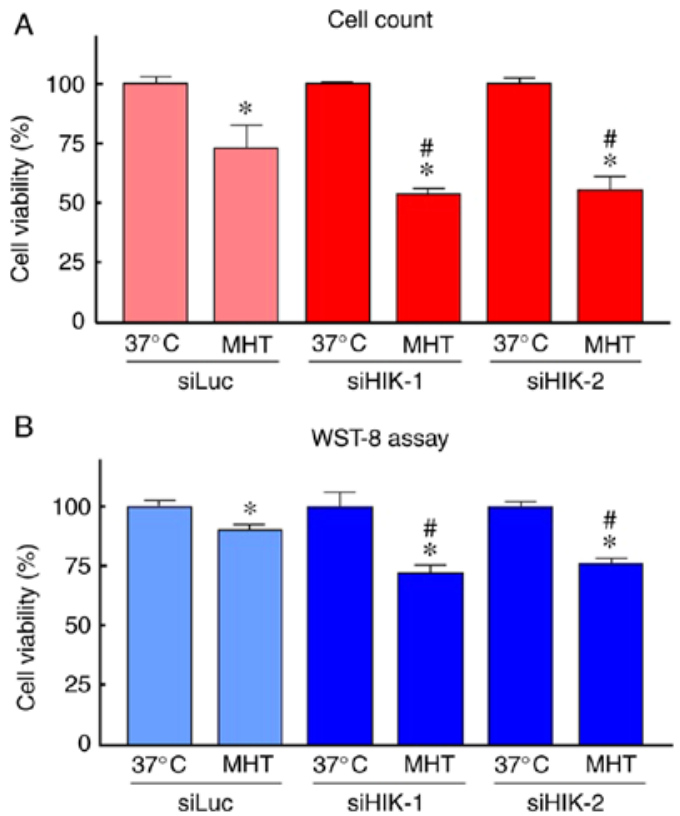

Figure 2. Effects of knockdown of HIKESHI on the viability in HSC-3 cells under mild hyperthermia (MHT) conditions. HIKESHI-knockdown HSC-3 cells were incubated at $42^{\circ} \mathrm{C}$ for $90 \mathrm{~min}$. The cell viability was evaluated $24 \mathrm{~h}$ after heating using (A) the trypan blue dye exclusion test or (B) WST-8 assay. Data are presented as mean \pm standard deviation $(\mathrm{n}=4-8) .{ }^{*} \mathrm{P}<0.05$ vs. each $37^{\circ} \mathrm{C}$-treated group; ${ }^{\prime \prime} \mathrm{P}<0.05$ vs. the siLuc-treated group at $42^{\circ} \mathrm{C}$. siLuc, siRNA for luciferase; siHIKE, siRNA for HIKESHI; HIKESHI, heat shock protein nuclear import factor hikeshi.
siHIK-1 nor siHIK-2 affected the intracellular localization of this protein under non-MHT conditions. Treatment of cells with MHT at $42^{\circ} \mathrm{C}$ for 60 min markedly induced the nuclear localization of Hsp70, as reported previously $(28,29)$. Furthermore, the MHT-induced nuclear localization was significantly inhibited in HIKESHI-KD cells (Fig. 3A and B). Next, cytoplasmic and nucleic fractions were prepared from the cells, and the protein levels were verified by western blot analysis. As expected, MHT at $42^{\circ} \mathrm{C}$ for $60 \mathrm{~min}$ induced the nuclear translocation of Hsp70, and this induction of Hsp70 translocation by MHT was significantly decreased in HIKESHI-KD cells (Fig. 4A and B).

Effects of HIKESHI-KD on HSF1 activation in HSC-3 cells. It is well known that the mobility shift and nuclear translocation of HSF1 due to its phosphorylation indicates activation of the molecule (42). In our experiments, either a mobility shift or nuclear translocation of HSF1 was observed immediately after MHT $\left(42^{\circ} \mathrm{C}\right.$ for $\left.60 \mathrm{~min}\right)$, whereas silencing of HIKESHI did not affect the activation of HSF1 under MHT conditions (Fig. 4A). Moreover, the effects of HIKESHI-KD on the gene expression of HIKESHI, HSPA1 and DNAJB1 were evaluated using RT-qPCR. The expression level of HIKESHI was slightly but significantly increased $3 \mathrm{~h}$ after MHT, to a level 1.3-fold higher compared with that of non-treated cells. As expected, the expression of HIKESHI was almost completely eradicated in HIKESHI-KD cells under MHT conditions (Fig. 5A). The 
A
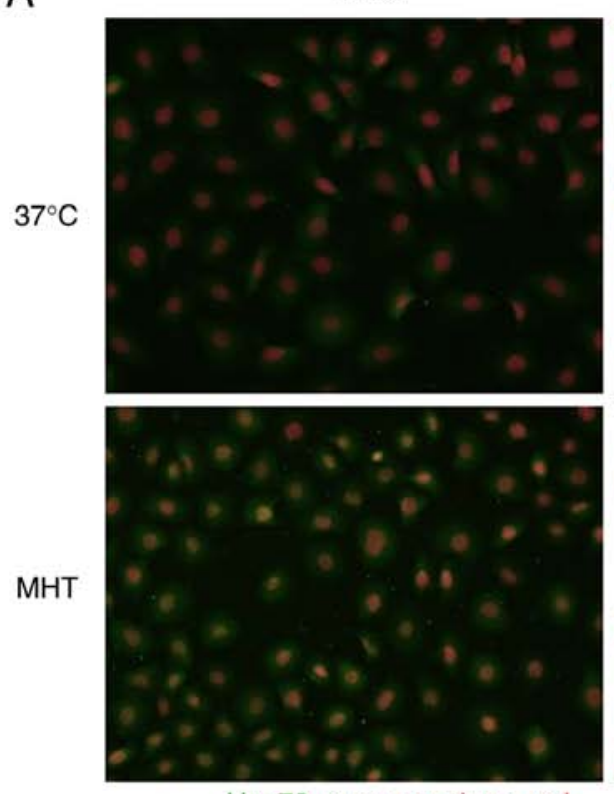

siHIK-1
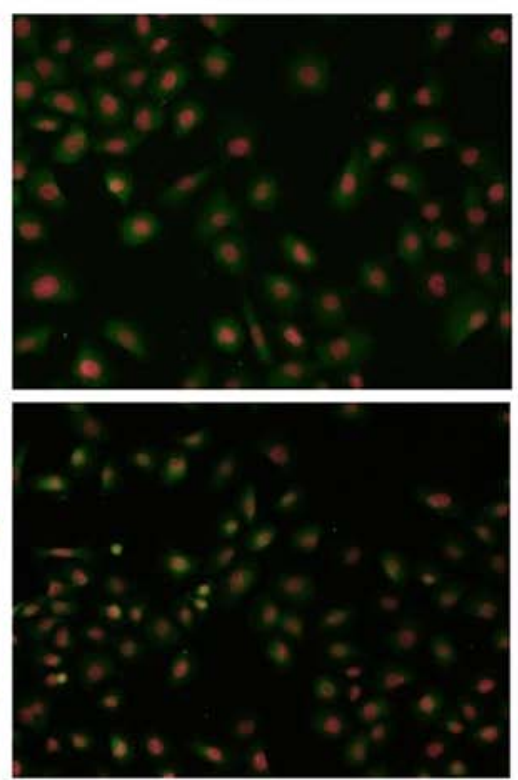

siHIK-2
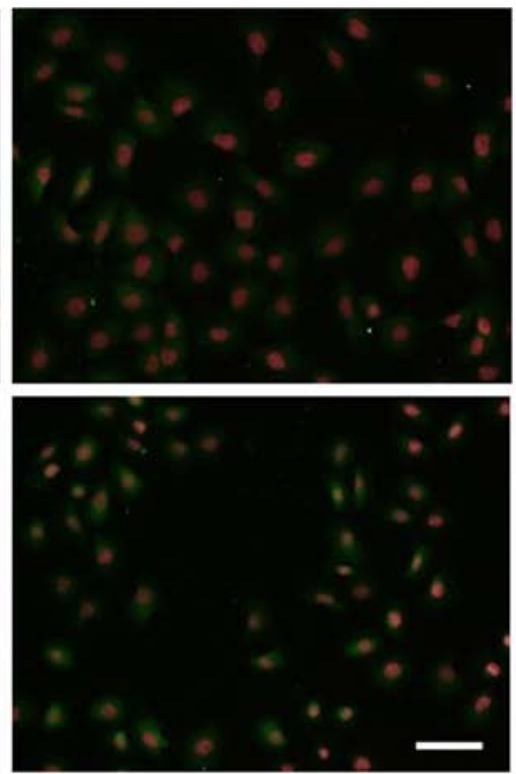

Hsp70, green; nucleus, red

B

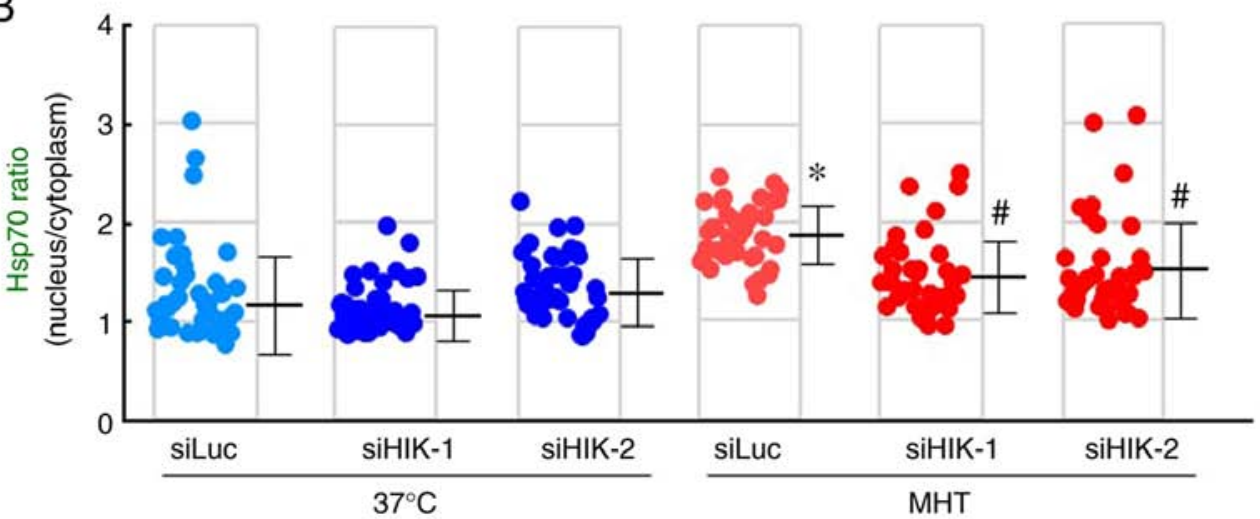

Figure 3. Immunocytochemical analysis of the localization of Hsp70 in HIKESHI-knockdown cells under mild hyperthermia (MHT) conditions. HIKESHI-knockdown HSC-3 cells were incubated at $42^{\circ} \mathrm{C}$ for $60 \mathrm{~min}$. The cells were fixed immediately after heat exposure. (A) Immunofluorescence staining with an antibody against Hsp70 (green) was performed. The nucleus was stained with DAPI, and pseudo-colored in red. Bar, $50 \mu \mathrm{m}$. (B) The fluorescence intensity of Hsp70 in either the nucleus or cytoplasm was measured, and the ratio (nucleus to cytoplasm) was calculated. Each value and means \pm standard deviation $(\mathrm{n}=40)$ are presented for each group. ${ }^{*} \mathrm{P}<0.05$ vs. the siLuc-treated group at $37^{\circ} \mathrm{C} ;{ }^{\prime \prime} \mathrm{P}<0.05$ vs. the siLuc-treated group at $42^{\circ} \mathrm{C}$. siLuc, siRNA for luciferase; siHIKE, siRNA for HIKESHI; HIKESHI, heat shock protein nuclear import factor hikeshi; Hsp70, heat shock protein $70 \mathrm{kDa}$.

expression levels of $H S P A l$ and $D N A J B l$ were markedly increased in a time-dependent-manner, by 66- and 40-fold, respectively, compared with the levels in non-treated cells. However, the expressions of these genes were not affected by HIKESHI-KD (Fig. 5B and C).

Effects of HIKESHI-KD on ERK2 activation in HSC-3 cells and the role of the MAPK/ERK pathway in the enhancement of MHT sensitivity by HIKESHI-KD. The expression levels of total and pERK1/2 proteins were assessed using western blot analysis. In HSC-3 cells, a relatively high expression level of total ERK2 (42 kDa) was observed, while total ERK1 (44 kDa) was hardly detected. ERK2 expression levels were almost constant under all the treatments tested. A significant and transient induction of pERK2 was observed immediately after MHT treatment $(0 \mathrm{~h})$. In addition, an elevated level of pERK2 was sustained for $0-1$ or $0-3 \mathrm{~h}$ after treatment in cells treated with siHIK-1 or siHIK-2, respectively (Fig. 6A and B). This increase in the level of pERK2 was completely abolished by pretreatment with U0126, a MAPK/ERK inhibitor, under both normal and MHT conditions (Fig. 7A). Next, the effects of U0126 on the viability of HIKESHI-KD cells were investigated and the results are shown in Fig. 7B. In control siLuc-treated cells, U0126 did not affect the cell viability under MHT conditions. By contrast, the inhibitor significantly decreased the viability of cells treated with the combination of HIKESHI-KD and MHT.

\section{Discussion}

The present study investigated whether silencing of HIKESHI by siRNA can sensitize human OSCC HSC-3 cells to MHT. The results demonstrated that the downregulation of HIKESHI enhanced MHT sensitivity, and inhibition of the MAPK/ERK 
A
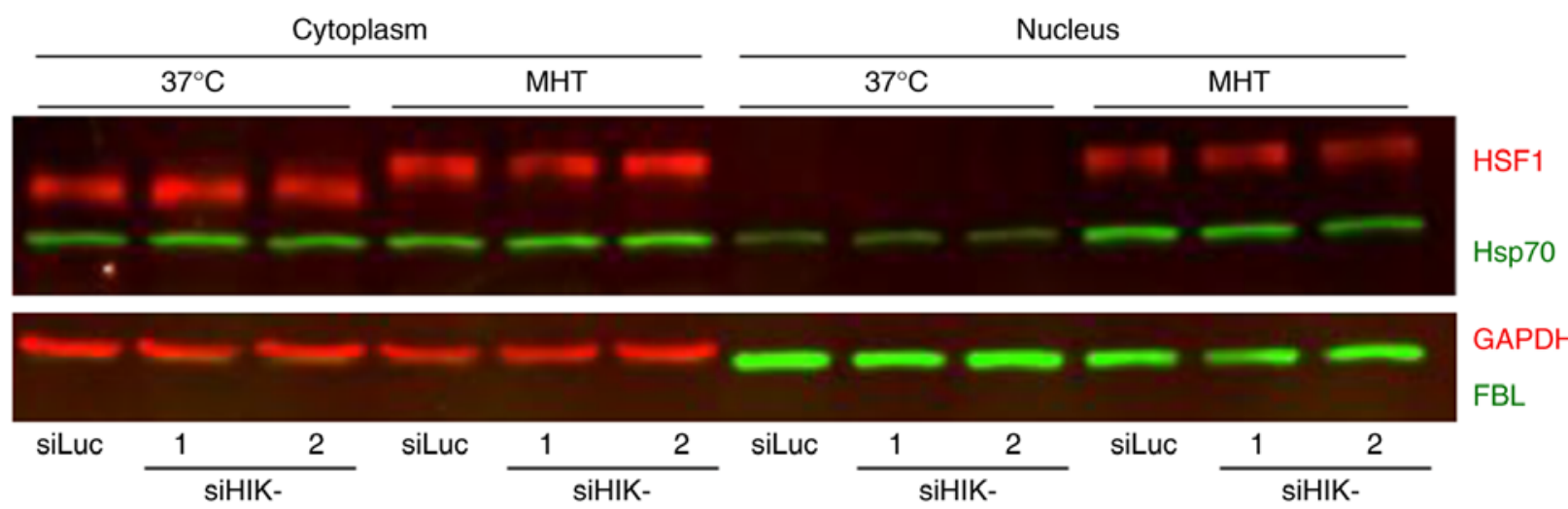

B

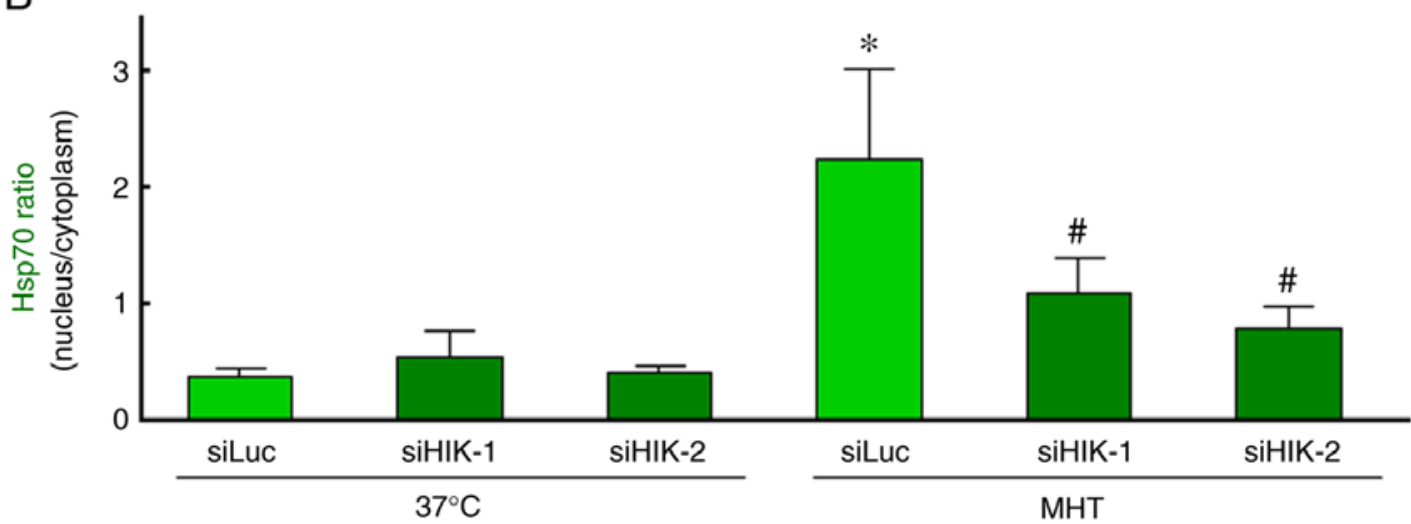

Figure 4. Western blot analysis of the intracellular localization of Hsp70 and HSF1 in HIKESHI-knockdown cells under mild hyperthermia (MHT) conditions. HIKESHI-knockdown HSC-3 cells were incubated at $42^{\circ} \mathrm{C}$ for $60 \mathrm{~min}$. Immediately after heat exposure, the cells were harvested and either the cytoplasmic or nuclear fraction was separated. (A) Western blotting was carried out using specific primary antibodies against Hsp70, HSF1, GAPDH and FBL. GAPDH and FBL served as marker proteins for the cytoplasm and nucleus, respectively. (B) Each band density of Hsp70 was quantified, and the ratio (nucleus to cytoplasm) was calculated. Data are presented as means \pm standard deviation $(\mathrm{n}=3)$. ${ }^{*} \mathrm{P}<0.05$ vs. the siLuc-treated group at $37^{\circ} \mathrm{C}$; ${ }^{*} \mathrm{P}<0.05$ vs. the siLuc-treated group at $42^{\circ} \mathrm{C}$. siLuc, siRNA for luciferase; siHIKE, siRNA for HIKESHI; HIKESHI, heat shock protein nuclear import factor hikeshi; Hsp70, heat shock protein $70 \mathrm{kDa}$; HSF, heat shock transcription factor; FBL, fibrillarin.

pathway further potentiated the synergistic effects of MHT and HIKESHI-KD.

HT and the combination of HT with radiotherapy, chemotherapy, or both, have been recognized as effective treatments for malignant tumors (1-10). However, the acquisition of thermotolerance constitutes a limitation of HT therapy (11-15). Although the detailed mechanisms are not well known, the induction of HSPs, particularly Hsp70, plays a central role in the acquisition of thermotolerance $(19,23)$. Therefore, Hsp70 has been considered as a valuable target in HT therapy (23). Furthermore, previous findings suggest the utilization of Hsp70 tumor antigens for cancer immunotherapy based on HT $(43,44)$. When the cells are exposed to heat stress, Hsp70 rapidly translocates from the cytoplasm into the nucleus $(28,29)$. Recently, HIKESHI was reported to be a nuclear import carrier of Hsp70 under heat stress conditions (30). In addition, previous reports demonstrated that HIKESHI expression was induced by HT in cancer cells $(30,32)$. These findings prompted us to investigate a unique strategy, namely MHT in combination with targeting of HIKESHI, which prevents only the nuclear translocation of Hsp70 under heat stress conditions. In the present study, it was confirmed that HIKESHI was induced at the mRNA level under MHT conditions. However, its induction ratio was markedly lower compared with those of HSPAI and DNAJBI, the expression levels of which are principally regulated by HSF1 $(21,22)$. These results indicated that heat may promote the expression of HIKESHI via HSF1-independent transcriptional mechanisms.

In line with previous reports (30-32), our experiments demonstrated that HIKESHI-KD did not affect the number of viable cells under normal conditions at $37^{\circ} \mathrm{C}$, suggesting that HIKESHI may not be required for the normal growth of OSCC HSC-3 cells. Interestingly, HIKESHI silencing significantly enhanced MHT sensitivity of HSC-3 cells, as demonstrated by the cell viability assay. These results were comparable to those of previous studies (30-32). Immunocytochemical analysis clearly demonstrated that HIKESHI-KD effectively prevented the nuclear translocation of Hsp70. This was confirmed by western blotting with the cellular fractionation assay. Of note, neither HSF1 activation nor HSP expression were affected by downregulation of HIKESHI under MHT conditions. Thus, disruption of the nuclear translocation of Hsp70 may play a major role in the enhancement of thermosensitivity by HIKESHI-KD. However, over half of HSC-3 cells were viable even after combined treatment with $\mathrm{MHT}\left(42^{\circ} \mathrm{C}\right.$ for $\left.90 \mathrm{~min}\right)$ and siRNA for HIKESHI. We previously reported that, under comparable experimental conditions, HSF1 silencing markedly enhanced MHT sensitivity, with damage occurring in 
A

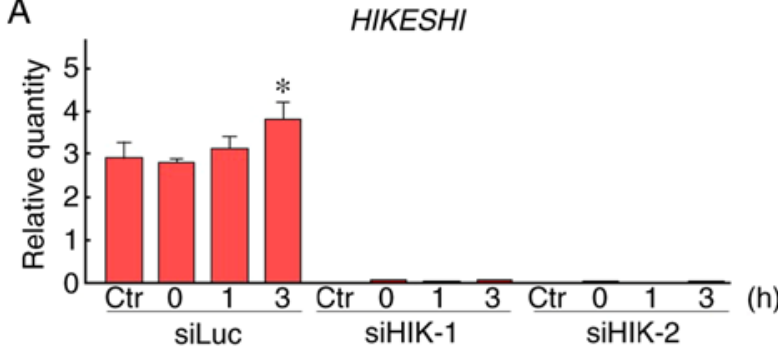

B
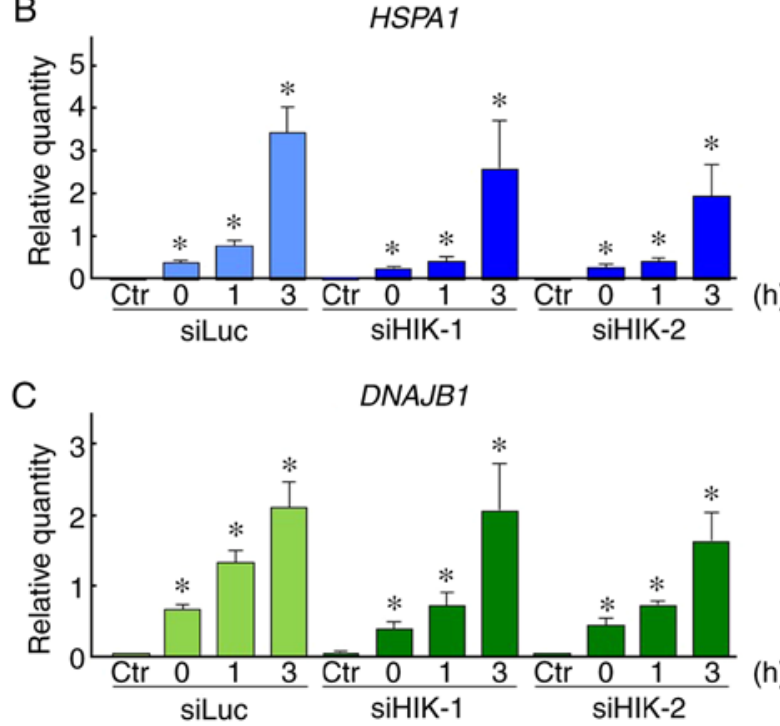

Figure 5. Effects of HIKESHI knockdown on the gene expression in mild hyperthermia (MHT)-treated HSC-3 cells. After treatment of HIKESHI-knockdown HSC-3 cells with mild hyperthermia at $42^{\circ} \mathrm{C}$ for $90 \mathrm{~min}$, the cells were cultured for 0,1 or $3 \mathrm{~h}$ at $37^{\circ} \mathrm{C}$. quantitative PCR was carried out with specific primers for (A) HIKESHI, (B) HSPA1, (C) DNAJBI and $G A P D H$. The expression level was normalized to that of GAPDH. siLuc, Data are presented as means \pm standard deviation $(n=4)$. Non-MHT-treated cells served as the control (Ctr). "P $<0.05$ vs. each Ctr. siRNA for luciferase; siHIKE, siRNA for HIKESHI; HIKESHI, heat shock protein nuclear import factor hikeshi; HSPA1, heat shock $70 \mathrm{kDa}$ protein 1; DNAJB1, DnaJ (Hsp40) homolog, subfamily B, member 1 .

$\sim 75 \%$ of HSC-3 cells treated with $\mathrm{MHT}\left(42^{\circ} \mathrm{C}\right.$ for $\left.90 \mathrm{~min}\right)$ and siRNA for HSF1 (25). Under these HSF1-silencing conditions, the expressions of HSF1-regulated proteins, such as Hsp70, Hsp40 and Hsp27, were maintained at a low level. It appears likely that the potential of HIKESHI-KD for enhancement of MHT is weaker compared with that of HSF1-KD.

The ERK $1 / 2$ cascade is a central signaling pathway activated by a wide variety of stressors, including heat (45-47). In the present study, although a significant increase in pERK2 was observed in HSC-3 cells treated with MHT, cells pretreated with U0126, an inhibitor of MAPK/ERK, exhibited little change in viability, which was consistent with the findings of previous studies using heat-treated cancer cells $(46,47)$. Chen et al (46) reported that pretreatment of human HT-29 colon cancer cells with U0126 resulted in enhancement of $\mathrm{HT}\left(43^{\circ} \mathrm{C}\right.$ for $\left.60 \mathrm{~min}\right)$ sensitivity in cells treated with a combination of HT and MG132, a proteasome inhibitor, suggesting that activated ERK is a prosurvival mechanism under conditions of combination of HT with proteasome inhibition. By contrast, ERK activity was reported to be a proapoptotic mechanism in human Y79 retinoblastoma cells treated with $\mathrm{HT}\left(44^{\circ} \mathrm{C}\right.$ for $\left.60 \mathrm{~min}\right)$ combined with

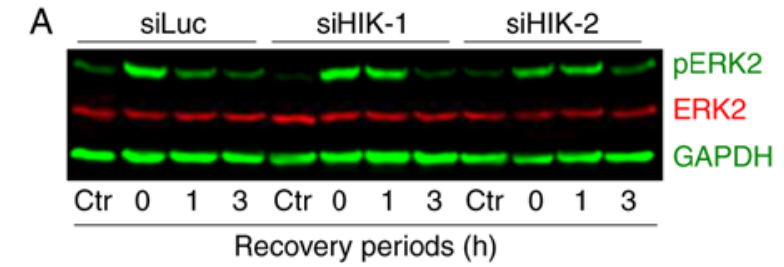

B

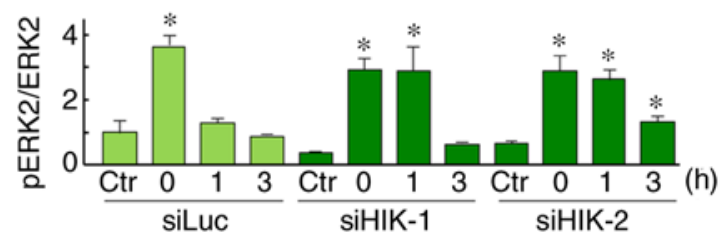

Figure 6. (A and B) Effects of HIKESHI knockdown on the ERK phosphorylation level in mild hyperthermia-treated HSC-3 cells. HIKESHI-knockdown HSC-3 cells were treated with mild hyperthermia (MHT) at $42^{\circ} \mathrm{C}$ for $90 \mathrm{~min}$, then cultured for 0,1 or $3 \mathrm{~h}$ at $37^{\circ} \mathrm{C}$. (A) Western blot analysis was performed with the specific primary antibodies for pERK1/2 (green), total ERK1/2 (red) and GAPDH (green). (B) Each band density of pERK2 or total ERK2 was quantified, and the ratio (pERK2 to total ERK2) was expressed. Data are presented as mean \pm standard deviation $(n=3)$. Non-MHT-treated cells served as the control (Ctr). ${ }^{*} \mathrm{P}<0.05$ vs. each Ctr. siLuc, siRNA for luciferase; siHIKE, siRNA for HIKESHI; HIKESHI, heat shock protein nuclear import factor hikeshi; ERK, extracellular signal-regulated kinase.
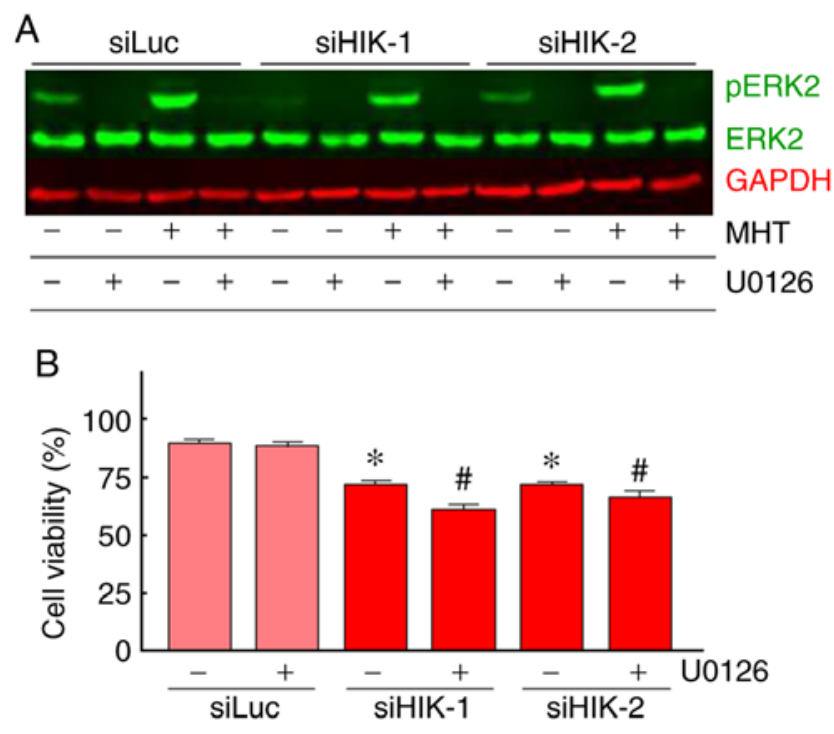

Figure 7. Effects of U0126 on the enhancement of mild hyperthermia (MHT) sensitivity induced by HIKESHI knockdown. (A and B) HIKESHI-knockdown HSC-3 cells were incubated at $37^{\circ} \mathrm{C}$ for $60 \mathrm{~min}$ in the culture medium containing U0126 $(10 \mu \mathrm{M})$ followed by incubation at $42^{\circ} \mathrm{C}$ for $90 \mathrm{~min}$ (MHT treatment). (A) Effects of U0126 on the ERK phosphorylation level in MHT-treated HSC-3 cells. The cells were harvested immediately after the MHT-treatment. Western blot analysis was performed with the specific primary antibodies for pERK1/2 (green), total ERK1/2 (green) and GAPDH (red). Typical results are shown. (B) The cell viability was evaluated $24 \mathrm{~h}$ after MHT using the WST- 8 assay. Data are presented as mean \pm standard deviation $(n=8)$. ${ }^{*} \mathrm{P}<0.05$ vs. the siLuc-treated group. ${ }^{\#} \mathrm{P}<0.05$ vs. each non-U0126-teated group. siLuc, siRNA for luciferase; siHIKE, siRNA for HIKESHI; HIKESHI, heat shock protein nuclear import factor hikeshi; ERK, extracellular signal-regulated kinase.

silencing of BAG cochaperone 3, a cochaperone for Hsp70 (47). In the present study, inhibition of the sustained activation of ERK by U0126 induced enhancement of MHT sensitivity in 
HSC-3 cells treated with a combination of MHT and siRNA for HIKESHI. These data suggest that the addition of HIKESHI silencing to MHT triggers ERK activation as a prosurvival mechanism, as reported previously (46). However, the molecular mechanism through which HIKESHI silencing induces the sustained activation of ERK under MHT conditions is unclear. Moreover, it has been demonstrated that nucleocytoplasmic transport is affected by the MAPK/ERK pathway under stress conditions $(48,49)$. At present, few details are known on the role of the MAPK/ERK pathway in the enhancement of MHT sensitivity by HIKESHI silencing.

In conclusion, the findings of the present study clearly demonstrated that downregulation of HIKESHI enhances the sensitivity to MHT in human OSCC HSC-3 cells; therefore, this molecule may be considered as a potential target in HT therapy of cancer. However, further studies are needed to investigate the detailed mechanisms underlying the effects of HIKESHI in HT therapy of cancer in animals and humans.

\section{Acknowledgements}

Not applicable.

\section{Funding}

The present study was supported in part by JSPS KAKENHI (grant nos. JP26560205 and JP17K01353).

\section{Availability of data and materials}

The datasets used and/or analyzed during the present study are available from the corresponding author on reasonable request.

\section{Authors' contributions}

YT designed all the experiments and wrote the manuscript. YT, KM, MT and SM performed the experiments. YT, KM and YF analyzed the data. All authors (YT, KM, MT, YF, TH, $\mathrm{SM}, \mathrm{TY}$ and $\mathrm{AH}$ ) have discussed the data and commented on the manuscript. All the authors have read and approved the final version of this manuscript.

\section{Ethics approval and consent to participate}

Not applicable.

\section{Patient consent for publication}

Not applicable.

\section{Competing interests}

The authors declare that they have no competing interests.

\section{References}

1. van der Zee J, González González D, van Rhoon GC, van Dijk JD, van Putten WL and Hart AA: Comparison of radiotherapy alone with radiotherapy plus hyperthermia in locally advanced pelvic tumours: A prospective, randomised, multicentre trial. Dutch Deep Hyperthermia Group. Lancet 355: 1119-1125, 2000.
2. Wust P, Hildebrandt B, Sreenivasa G, Rau B, Gellermann J, Riess H, Felix R and Schlag PM: Hyperthermia in combined treatment of cancer. Lancet Oncol 3: 487-497, 2002.

3. Issels RD: Hyperthermia adds to chemotherapy. Eur J Cancer 44: 2546-2554, 2008.

4. Zagar TM, Oleson JR, Vujaskovic Z, Dewhirst MW, Craciunescu OI, Blackwell KL, Prosnitz LR and Jones EL: Hyperthermia combined with radiation therapy for superficial breast cancer and chest wall recurrence: A review of the randomised data. Int J Hyperthermia 26: 612-617, 2010.

5. Westermann A, Mella O, Van Der Zee J, Jones EL, Van Der Steen-Banasik E, Koper P, Uitterhoeve AL, De Wit R, Van Der Velden J, Burger C, et al: Long-term survival data of triple modality treatment of stage IIB-III-IVA cervical cancer with the combination of radiotherapy, chemotherapy and hyperthermia-an update. Int J Hyperthermia 28: 549-553, 2012.

6. Ahmed K, Tabuchi Y and Kondo T: Hyperthermia: An effective strategy to induce apoptosis in cancer cells. Apoptosis 20: 1411-1419, 2015.

7. Ohguri T, Harima Y, Imada H, Sakurai H, Ohno T, Hiraki Y, Tuji K, Tanaka M and Terashima H: Relationships between thermal dose parameters and the efficacy of definitive chemoradiotherapy plus regional hyperthermia in the treatment of locally advanced cervical cancer: Data from a multicentre randomised clinical trial. Int J Hyperthermia 34: 461-468, 2018.

8. Bakker A, van der Zee J, van Tienhoven G, Kok HP, Rasch CRN and Crezee $\mathrm{H}$ : Temperature and thermal dose during radiotherapy and hyperthermia for recurrent breast cancer are related to clinical outcome and thermal toxicity: A systematic review. Int J Hyperthermia 36: 1024-1039, 2019.

9. Tohnai I, Hayashi Y, Mitsudo K, Shigetomi T, Ueda M and Ishigaki T: Prognostic evaluation of preoperative thermochemoradiotherapy for $\mathrm{N}(3)$ cervical lymph node metastases of oral cancer. Oncology 62: 234-240, 2002.

10. Nozato T, Koizumi T, Hayashi Y, Iida M, Iwai T, Oguri S, Hirota M, Kioi M, Koike I, Hata M, et al: Thermochemoradiotherapy using superselective intra-arterial infusion for patients with oral cancer with cervical lymph node metastases. Anticancer Res 39: 1365-1373, 2019.

11. Urano M: Kinetics of thermotolerance in normal and tumor tissues: A review. Cancer Res 46: 474-482, 1986.

12. Sapareto SA: Thermal isoeffect dose: Addressing the problem of thermotolerance. Int J Hyperthermia 3: 297-305, 1987.

13. Overgaard J: The current and potential role of hyperthermia in radiotherapy. Int J Radiat Oncol Biol Phys 16: 535-549, 1989.

14. Li GC, Mivechi NF and Weitzel G: Heat shock proteins, thermotolerance, and their relevance to clinical hyperthermia. Int J Hyperthermia 11: 459-488, 1995.

15. Li GC and Calderwood SK: Hyperthermia classic article commentary: 'Re-induction of hsp70 synthesis: An assay for thermotolerance' by Gloria C. Li and Johnson Y. Mak, International Journal of Hyperthermia 1989;5:389-403. Int J Hyperthermia 25: 258-261, 2009.

16. Lindquist $\mathrm{S}$ and Craig EA: The heat-shock proteins. Annu Rev Genet 22: 631-677, 1988.

17. Ohtsuka $\mathrm{K}$ and Hata M: Molecular chaperone function of mammalian Hsp70 and Hsp40-a review. Int J Hyperthermia 16: 231-245, 2000.

18. Hartl FU and Hayer-Hartl M: Molecular chaperones in the cytosol: From nascent chain to folded protein. Science 295: $1852-1858,2002$

19. Kregel KC: Heat shock proteins: Modifying factors in physiological stress responses and acquired thermotolerance. J Appl Physiol (1985) 92: 2177-2186, 2002.

20. Kampinga HH, Hageman J, Vos MJ, Kubota H, Tanguay RM, Bruford EA, Cheetham ME, Chen B and Hightower LE: Guidelines for the nomenclature of the human heat shock proteins. Cell Stress Chaperones 14: 105-111, 2009.

21. Akerfelt M, Morimoto RI and Sistonen L: Heat shock factors: Integrators of cell stress, development and lifespan. Nat Rev Mol Cell Biol 11: 545-555, 2010.

22. Fujimoto $M$ and Nakai A: The heat shock factor family and adaptation to proteotoxic stress. FEBS J 277: 4112-4125, 2010.

23. Calderwood SK and Asea A: Targeting HSP70-induced thermotolerance for design of thermal sensitizers. Int J Hyperthermia 18: 597-608, 2002.

24. McMillan DR, Xiao X, Shao L, Graves K and Benjamin IJ: Targeted disruption of heat shock transcription factor 1 abolishes thermotolerance and protection against heat-inducible apoptosis. J Biol Chem 273: 7523-7528, 1998. 
25. Tabuchi Y, Furusawa Y, Wada S, Ohtsuka K and Kondo T: Silencing heat shock transcription factor 1 using small interfering RNA enhances mild hyperthermia and hyperthermia sensitivity in human oral squamous cell carcinoma cells. Thermal Med 27: 99-108, 2011.

26. Bettaieb A and Averill-Bates DA: Thermotolerance induced at a mild temperature of $40^{\circ} \mathrm{C}$ alleviates heat shock-induced ER stress and apoptosis in HeLa cells. Biochim Biophys Acta 1853: $52-62,2015$.

27. Matozaki M, Saito Y, Yasutake R, Munira S, Kaibori Y, Yukawa A, Tada $M$ and Nakayama Y: Involvement of Stat3 phosphorylation in mild heat shock-induced thermotolerance. Exp Cell Res 377: 67-74, 2019.

28. Pelham HR: Hsp70 accelerates the recovery of nucleolar morphology after heat shock. EMBO J 3: 3095-3100, 1984.

29. Welch WJ and Feramisco JR: Nuclear and nucleolar localization of the 72,000-dalton heat shock protein in heat-shocked mammalian cells. J Biol Chem 259: 4501-4513, 1984.

30. Kose S, Furuta M and Imamoto N: Hikeshi, a nuclear import carrier for Hsp70s, protects cells from heat shock-induced nuclear damage. Cell 149: 578-589, 2012.

31. Rahman KMZ, Mamada $\mathrm{H}$, Takagi M, Kose $\mathrm{S}$ and Imamoto $\mathrm{N}$ : Hikeshi modulates the proteotoxic stress response in human cells: Implication for the importance of the nuclear function of HSP70s. Genes Cells 22: 968-976, 2017.

32. Yanoma T, Ogata K, Yokobori T, Ide M, Mochiki E, Toyomasu Y, Yanai M, Kogure N, Kimura A, Suzuki M, et al: Heat shock-induced HIKESHI protects cell viability via nuclear translocation of heat shock protein 70. Oncol Rep 38: 1500-1506, 2017.

33. Bhalla S, Chaudhary K, Kumar R, Sehgal M, Kaur H, Sharma S and Raghava GP: Gene expression-based biomarkers for discriminating early and late stage of clear cell renal cancer. Sci Rep 7: 44997, 2017.

34. Tabuchi Y, Wada S, Furusawa Y, Ohtsuka K and Kondo T: Gene networks related to the cell death elicited by hyperthermia in human oral squamous cell carcinoma HSC-3 cells. Int J Mol Med 29: 380-386, 2012

35. Yunoki T, Kariya A, Kondo T, Hayashi A and Tabuchi Y: The combination of silencing BAG3 and inhibition of the JNK pathway enhances hyperthermia sensitivity in human oral squamous cell carcinoma cells. Cancer Lett 335: 52-57, 2013.

36. Yunoki T, Tabuchi Y, Hayashi A and Kondo T: Network analysis of genes involved in the enhancement of hyperthermia sensitivity by the knockdown of BAG3 in human oral squamous cell carcinoma cells. Int J Mol Med 38: 236-242, 2016

37. Suzuki K, Bose P, Leong-Quong RY, Fujita DJ and Riabowol K: REAP: A two minute cell fractionation method. BMC Res Notes 3: 294, 2010.

38. Chang KL, Wong LR, Pee HN, Yang S and Ho PC: Reverting metabolic dysfunction in cortex and cerebellum of APP/PS1 mice, a model for Alzheimer's disease by pioglitazone, a peroxisome proliferator-activated receptor gamma (PPAR $\gamma$ ) agonist. Mol Neurobiol 56: 7267-7283, 2019
39. Yap K, Mukhina S, Zhang G, Tan JSC, Ong HS and Makeyev EV: A short tandem repeat-enriched RNA assembles a nuclear compartment to control alternative splicing and promote cell survival. Mol Cell 72: 525-540.e13, 2018.

40. Furusawa Y, Yunoki T, Hirano T, Minagawa S, Izumi H, Mori H, Hayashi A and Tabuchi Y: Identification of genes and genetic networks associated with BAG3-dependent cell proliferation and cell survival in human cervical cancer HeLa cells. Mol Med Rep 18: 4138-4146, 2018.

41. Hirano T, Minagawa S, Furusawa Y, Yunoki T, Ikenaka Y, Yokoyama T, Hoshi N and Tabuchi Y: Growth and neurite stimulating effects of the neonicotinoid pesticide clothianidin on human neuroblastoma SH-SY5Y cells. Toxicol Appl Pharmacol 383: 114777, 2019.

42. Sarge KD, Murphy SP and Morimoto RI: Activation of heat shock gene transcription by heat shock factor 1 involves oligomerization, acquisition of DNA-binding activity, and nuclear localization and can occur in the absence of stress. Mol Cell Biol 13: 1392-1407, 1993.

43. Todryk SM, Gough MJ and Pockley AG: Facets of heat shock protein 70 show immunotherapeutic potential. Immunology 110: $1-9,2003$.

44. Ito $\mathrm{A}$, Honda $\mathrm{H}$ and Kobayashi $\mathrm{T}$ : Cancer immunotherapy based on intracellular hyperthermia using magnetite nanoparticles: A novel concept of 'heat-controlled necrosis' with heat shock protein expression. Cancer Immunol Immunother 55: 320-328, 2006.

45. Deschênes-Simard X, Kottakis F, Meloche S and Ferbeyre G: ERKs in cancer: Friends or foes? Cancer Res 74: 412-419, 2014.

46. Chen F, Rezavi R, Wang CC and Harrison LE: Proteasome inhibition potentiates the cytotoxic effects of hyperthermia in HT-29 colon cancer cells through inhibition of heat shock protein 27. Oncology 73: 98-103, 2007.

47. Yunoki T, Tabuchi Y, Hayashi A and Kondo T: BAG3 protects against hyperthermic stress by modulating NF- $\kappa B$ and ERK activities in human retinoblastoma cells. Graefes Arch Clin Exp Ophthalmol 253: 399-407, 2015.

48. Czubryt MP, Austria JA and Pierce GN: Hydrogen peroxide inhibition of nuclear protein import is mediated by the mitogen-activated protein kinase, ERK2. J Cell Biol 148: 7-16, 2000.

49. Kosako H, Yamaguchi N, Aranami C, Ushiyama M, Kose S, Imamoto N, Taniguchi H, Nishida E and Hattori S: Phosphoproteomics reveals new ERK MAP kinase targets and links ERK to nucleoporin-mediated nuclear transport. Nat Struct Mol Biol 16: 1026-1035, 2009.

This work is licensed under a Creative Commons Attribution-NonCommercial-NoDerivatives 4.0 International (CC BY-NC-ND 4.0) License. 